\title{
EDUCAR PELA PARTICIPACÃO, DEMOCRATIZAR O PODER: O LEGADO FREIREANO NA GESTÃO PÚBLICA
}

\author{
Danilo Romeu Streck \\ Sandro de Castro Pitano** \\ Cheron Zanini Moretti***
}

RESUMO: A educação popular foi uma propulsora importante nas reformas políticas na América Latina nessas últimas décadas. Dessa relação com o poder público deriva-se também uma nova relação com o estado, colocandose esse tema como um importante desafio teórico-prático atual. Nesse trabalho, analisa-se a presença do legado de Paulo Freire, uma referência central na educação popular, por meio de investigação empírica junto ao Orçamento Participativo e ao Sistema Estadual de Participação Popular e Cidadã (SISPARCI), no estado do Rio Grande do Sul, Brasil, tanto no que tange à sua formulação, quanto à sua efetivação em práticas sociais. O desafio consiste em compreender, com base na concepção freireana, se as experiências de participação analisadas desenvolvem processos formativos voltados para a democratização do poder. Os resultados, conforme explicitado no artigo, apontam uma série de fatores que limitam ou inibem o seu potencial formativo. Palavras-chave: Paulo Freire. Políticas públicas. Participação. Educação popular. Poder.

EDUCATIONG THROUGH PARTICIPATION, DEMOCRATIZING POWER: FREIREAN LEGACY IN PUBLIC ADMINISTATION

ABSTRACT: Popular education was an important force in the promotion of political reforms in Latin America in the last decades. This relation with the established public powers also originates a new relation with the state, thus this theme becoming presently an important practical-theoretical challenge. In this paper, we analyze the presence and legacy of Paulo Freire, a central reference in popular education, through empirical research in

\footnotetext{
"Doutor em Educação pela Rutgers University (NJ). Professor pesquisador do Programa de Pós-Graduação em Educação da Universidade do Vale do Rio dos Sinos (Unisinos). Coordenador do Grupo de Pesquisa “Mediações pedagógicas e cidadania”. E-mail:<dstreck@unisinos.br > .

"* Doutor em Educação (UFRGS). ProfessorAssociado do Instituto de Ciências Humanas da Universidade Federal de Pelotas (UFPel). E-mail:<scpitano@gmail.com>.

*** Doutora em Educação (UNISINOS).Professora pesquisadora no Programa de Pós-Graduação em Educação da Universidade de Santa Cruz do Sul (UNISC).E-mail: < cheron@unisc.br > .
} 
participatory budget (PB)and in the State System of Popular and Citizen Participation in Rio Grande do Sul, Brazil as much in its formulation as in its effectivenessin social practices. The challenge is to understand, based on Freire's assumptions, whether the observed experiences of participation have developed educational processes that promote the democratization of power. The results, as mentioned in the article, point to a series of factors that limit or inhibit the formative potential of the process.

Keywords: Paulo Freire. Public policies. Participation. Popular education. Power.

\section{INTRODUCุÃO}

A participação passou a fazer parte de políticas sociais e de muitos projetos de governo no Brasil nestas últimas décadas. Foram movimentos sociais populares que mobilizaram a opinião pública, políticos e gestores para que canais e instrumentos de participação fossem incorporados no texto da Constituição de 1988, prevendo, por exemplo, a participação popular na formulação de políticas sociais, dentre outras, das políticas públicas de saúde, assistência social, educação e direitos da criança e do adolescente, através de respectivos conselhos.

Este movimento político em boa medida se confunde com a história da educação popular que teve, na obra de Paulo Freire, uma de suas principais referências. Neste estudo queremos explorar como a pedagogia freireana se faz presente em processos de participação popular nas decisões sobre a destinação do orçamento público. Não se trata apenas de confirmar o legado de Freire na gestão pública, mas também de verificar como a sua pedagogia pode continuar sendo uma força inspiradora para novas práticas de participação e de partilha de poder. As recentes manifestações de rua (2013), no Brasil, o descrédito da representação no âmbito das instituições políticas e as insatisfações com as formas de gestão da coisa pública colocam-nos diante do desafio de revisitar políticas e projetos cuja execução nem sempre - ou raramente - corresponde à sua intencionalidade original. $\mathrm{Na}$ medida em que a pedagogia freireana embasa algumas políticas, cabe analisar o que dela é apropriado e como se dá essa apropriação.

Neste artigo questionamos as possibilidades e os limites da participação e, consequentemente, da democratização do poder por meio de experiências como as do Orçamento Participativo (OP) e a do Sistema Estadual de Participação Popular e Cidadã (SISPARCI), no estado do Rio Grande do Sul. Não temos a pretensão de descrever o processo de desenvolvimento dessas experiências de participação popular na gestão pública, mas nos atemos ao pressuposto comum 
entre as mesmas: criar espaços de participação para a co-partilha do poder na administração da coisa pública, ainda que os espaços e dimensões da participação, em cada uma dessas ferramentas, sejam distintos. Com Freire (2003), lembramos que o aprendizado da democracia necessita de experiências de participação; aprendemos democracia pela prática da decisão, da crítica, da denúncia e do anúncio, tensionados entre liberdade e autoridade. Democratizar o poder político é, diante da tradição autoritária, deslocá-lo de sua característica vertical por meio da participação, princípio pedagógico da democracia freireana, que aponta para a superação do paradigma representativo (BOBBIO, 1986, p. 44), cujo esgotamento tem sido explicitado no Brasil, nos últimos anos.

O argumento central deste trabalho é que a relação da proposta pedagógica de Paulo Freire com as políticas voltadas para a gestão pública é uma relação de fortes tensionamentos e contradições. Por um lado, a vida em sociedades democráticas implica na regulamentação da vida pública, inclusive das formas de participação. Por outro lado, essa mesma regulamentação pode servir como fator de inibição de uma participação autêntica. Trata-se, na definição de Boaventura de Sousa Santos, da disputa entre forças de regulação e de emancipação (SANTOS, 2000) ${ }^{1}$.

Analisamos, para tanto, os dados coletados na investigação sobre duas experiências participativas de gestão pública no estado do Rio Grande do Sul, lideradas pelo Partido dos Trabalhadores (PT): o Orçamento Participativo (OP), implementado entre os anos de 1999 e 2002 e o Sistema Estadual de Participação Cidadã (SISPARCI), entre os anos de 2011 e 2014. Os dados foram obtidos junto a assembleias e audiências municipais e regionais, entrevistas, questionários e reuniões de pesquisa com os coordenadores e participantes dos processos. Paralelamente, empreendeu-se também um estudo sobre a presença de Paulo Freire no Rio Grande do Sul, tanto na sua participação direta quanto na subsequente produção acadêmica. ${ }^{2}$

A investigação sobre experiências de gestão pública perpassadas por processos participativos, tais como o OP e o SISPARCI ${ }^{3}$, possui grande relevância científica e social em tempos de crise do modelo democrático representativo. Historicamente construído sobre os pilares do autoritarismo e da negação do protagonismo social, o Brasil se consolidou como democracia em meio a uma tradição elitista, cuja ruptura depende da participação dos sujeitos no processo político, para além do sistema partidário. Com Paulo Freire, sustentamos a crença no poder transformador do protagonismo popular, dimensão que permeou toda essa investigação. Cabe destacar que as administrações públicas em permanente alternância - de 
princípios políticos, econômicos e ideológicos, por exemplo, acabam caracterizando a existência de lacunas de compromisso na gestão pública, as quais somente podem ser superadas pela continuidade existencial da participação popular. Portanto, a compreensão dessas experiências a partir de uma análise rigorosa, ao apontar seus limites e possibilidades em relação à descentralização do poder, revela-se fundamental para a disseminação de iniciativas cada vez mais sólidas de construção de uma nova democracia, pautada pela participação direta e pelo empoderamento popular.

Organizamos o artigo em três partes: na primeira, Educar pela participação: decisão e distribuição do orçamento público, abordamos aspectos históricos de alguns instrumentos de descentralização de poder e tomada de decisões sobre o orçamento público, no Rio Grande do Sul; em seguida, em Paulo Freire e a participação, relacionamos as ideias políticas e pedagógicas desse educador com a de participação para, por fim, apresentar alguns apontamentos sobre as Contradiçoes e tensionamentos na prática de participação como possibilidade de democratização do poder.

\section{EDUCAR PELA PARTICIPAC̣ÃO: DECISÃO E DISTRIBUIC̣ÃO DO ORÇAMENTO PÚBLICO}

O orçamento participativo (OP) pode ser compreendido como uma ferramenta de descentralização do poder através da participação popular nas tomadas de decisão sobre o orçamento público. Mas também pode ser compreendido como resultado de um movimento social e político que busca avançar na consolidação da emergente esfera pública controlada pela participação popular. No campo da teoria sobre democracia, de acordo com Weyh (2011), tal experiência tem recebido atenção e merecido relevância em três tipos de debates: 1) sobre a relação: sociedade civil e democracia local; 2) sobre o desenho institucional; e, 3) sobre o aprofundamento da democracia. A ênfase na dimensão democrática do OP tanto pode estar relacionada à emergência de experiências de gestões populares, sobretudo locais, a partir da década de 1990, quanto à inexperiência democrática das décadas anteriores.

O OP, que tomamos como uma das referências neste artigo, não pode ser entendido sem a vinculação com a transição da sociedade brasileira de fechada para aberta. Em outros termos, trata-se de uma "parte de um longo processo de luta pela participação popular, uma vez que, desde as décadas de 1960 e 1970, a participação foi bandeira de muitos grupos que se debatiam por um projeto político construído a partir das bases" (STRECK, 2005). Foram práticas que buscavam a ruptura com uma sociedade historicamente fechada. 
Assim, é importante relacionar seu surgimento com a construção do Partido dos Trabalhadores (PT), a Central Única dos Trabalhadores (CUT) e o Movimento dos Trabalhadores Rurais Sem Terra (MST), nos anos de 1980. O partido, cuja fundação teve Paulo Freire entre seus membros, e os movimentos sociais populares da cidade e do campo, respectivamente, foi responsável por organizar boa parte da esquerda social e radical no período de redemocratização brasileira. Seu projeto de governo consistia na organização e no fortalecimento dos conselhos populares como forma de ocupação da institucionalidade para apoiar a luta da classe trabalhadora, promovendo a inversão de prioridades (SOUTO, 2013, p. 162).

A luta por amplos direitos através do movimento de emersão das massas organizadas e a conquista de governos municipais e estaduais pelo PT, nas duas décadas seguintes, lograram construir alguns dispositivos de controle social sobre a coisa pública. O orçamento participativo foi um desses e, talvez, o mais importante. Esses dispositivos foram herdeiros do avanço das lutas e das organizações de bases das décadas de 1960 e 1970, que de modo geral ofereceram os pilares necessários para o aprimoramento da democracia. Não são poucos os registros que apontam a experiência de resistência com bases comunitárias e participativas que visavam ações mobilizadoras (WEYH, 2011). A Federação Rio-Grandense de Associações Comunitáriasde Amigos de Bairros (FRACAB), de 1959, e a União de Associações de Moradores de Porto Alegre (UAMPA), de 1983, por exemplo, são expressões políticas de práticas associativas que tinham na democracia direta, com base na realização de assembleias, formas de organização da vida em comunidade no meio urbano.

A experiência do OP em âmbito estadual, dez anos após ter sido realizado em Porto Alegre, credenciou esse mecanismo a ser uma das experiências mais desenvolvidas de democracia participativa, uma vez que combina formas de participações delegadas, ou seja, por representações, com formas de participações diretas ${ }^{4}$ no processo democrático. A participação é, portanto, o eixo desse processo que inclui: diagnóstico das demandas da comunidade, ou seja, pesquisa; organização das demandas e do orçamento disponível, portanto, planejamento; participação direta e representativa em assembleias regionais e locais para a tomada de decisões sobre o orçamento público e na fiscalização da execução das demandas escolhidas, logo, democratização da gestão pública.

Para além do campo da teoria da democracia, é pertinente identificar no OP traços de uma pedagogia da participação. Através da participação direta nas assembleias locais ou regionais do OP as pessoas 
passam a "dizer a sua palavra". Tal assertiva pode ser contemplada nas inúmeras situações em que os participantes, lideranças comunitárias ou de base, tomam o microfone para defender as demandas necessárias para resolução de problemas concretos da comunidade, apropriando-se, no processo, sobre o funcionamento da burocracia estatal. Nesse exemplo, percebemos a presença da pedagogia freireana que se sustenta, entre vários princípios, no processo de tomada de consciência, do homem e da mulher, como sujeitos fazedores de sua própria história. Mais uma vez, no referido exemplo, através da palavra autêntica daqueles e daquelas que, partindo da sua realidade, com a propriedade dos seus argumentos, agem no mundo com os outros e as outras que se encontram naquele lugar.

A participação acontece porque já se tem experiências prévias de participação na comunidade, mas acontece também pela "novidade" do espaço, pelo convívio, pela possibilidade de negociação e de sociabilidade; acontece ainda pelo "prazer do encontro", mas também pelas necessidades de resolução de problemas concretos. Em uma assembleia popular se manifestam elementos da cultura regional e, quase que naturalmente, se (re)criam ritos de convivência. De acordo com Streck (2005), as assembleias nos remetem às observações de Karl Marx sobre as reuniões de trabalhadores que apesar do objetivo imediato da instrução, organização, propaganda, entre outros - passam a ter uma nova necessidade, a de associação. Aquilo que parecia ser um meio passa a ser um fim. "A companhia, a associação, a conversa, que por sua vez têm a sociedade como objetivo, são o que basta para ele" (MARX apud EAGLETON, 1999, p.22). Assim como acontece na roda de chimarrão, na conversa entre jovens ou no encontro entre professores e professoras após o horário de trabalho. Na participação das assembleias, expressam-se as necessidades e problemas cotidianos, bem como a construção de uma visão social de mundo alargada em relação ao que parece ser pontual. O acompanhamento das assembleias do orçamento participativo no Rio Grande do Sul aponta tanto para seu papel estratégico na busca pela satisfação das necessidades concretas, quanto para a dimensão pedagógica presente na participação.

A ruptura desse processo com a escolha de outro governo estadual, com outras propostas e prioridades, foi acompanhada pela institucionalização da consulta popular sobre a utilização dos recursos públicos. Comprometido o processo amplo de participação direta com a participação representativa no controle social das políticas públicas e do orçamento estatal, anos mais tarde se criou um sistema 
para retomar as dimensões participativas diretas, representativas e consultivas, incluindo os meios digitais, a que passamos a conhecer como SISPARCI. Através de Decreto ${ }^{5}$, diferentemente do Orçamento Participativo, estabeleceram-se as diretrizes da participação popular e cidadã para: 1) a elaboração, monitoramento e avaliação das políticas públicas; 2) a promoção da transversalidade na execução dessas políticas; 3) a articulação entre as democracias participativa e representativa; 4) a realização de reuniões plenárias; 5) manifestação popular através do voto; 6) a presença estruturada da administração do estado do Rio Grande do Sul em todas as regiões; 7) a busca de eficiência e de eficácia na execução das políticas públicas; e, por fim, 8) a busca do diálogo qualificado e sistemático com a sociedade gaúcha.

A figura 1 retrata o número de participações na votação de prioridades no estado do Rio Grande do Sul entre os anos de 2011 e 2014. O levantamento é do governo do estado e inclui uma consulta, pela internet, sobre a eventual reforma política no Brasil, isto é, agrega participantes de outra modalidade aos números que indicam participação na definição do orçamento.

FIGURA 1 - Participações na Votação de Prioridades - RS (2011-2014)

\begin{tabular}{|l|r|r|r|r|}
\hline Ano/Modalidade & \multicolumn{1}{|c|}{$\mathbf{2 0 1 1}$} & \multicolumn{1}{|c|}{$\mathbf{2 0 1 2}$} & \multicolumn{1}{c|}{$\mathbf{2 0 1 3}$} & \multicolumn{1}{c|}{$\mathbf{2 0 1 4}$} \\
\hline Presencial & 998.145 & 907.146 & 967.610 & 1.059 .842 \\
\hline Internet & 135.996 & 119.603 & 157.549 & 255.751 \\
\hline Total de votantes & 1.134 .141 & 1.026 .749 & 1.125 .129 & 1.315 .593 \\
\hline
\end{tabular}

Fonte: Secretaria de Planejamento, Gestão e Participação Cidadã - RS (2014)

Considerando a população total do Estado, estimada em 11, 2 milhões de pessoas ${ }^{6}$, os números revelam um volume significativo de participantes, equivalendo, na média anual, a cerca de dez por cento. Os anos 2013 e 2014 demonstram uma tendência ascendente da participação, tanto presencial como pela internet, embora nesta estejam incluídos os números da consulta sobre a reforma política, inexistente nos primeiros dois anos (2011 e 2012).

Já a figura 2 evidencia os dados obtidos por meio de questionários aplicados durante as reuniões plenárias do SISPARCI nos municípios de Novo Hamburgo e São Leopoldo, referentes à existência ou não de vínculo do participante com instituição e a forma como soube da reunião, vindo a participar. 
FIGURA 2 - Assembleias em Novo Hamburgo e São Leopoldo (2012)

\begin{tabular}{|c|c|c|c|c|c|}
\hline \multicolumn{2}{|c|}{ Representa Instituição? } & \multicolumn{4}{|c|}{ Como soube da assembleia? } \\
\hline Sim & Não & $\begin{array}{c}\text { Convite } \\
\text { pessoal }\end{array}$ & Internet & Jornal & Outros \\
\hline 100 & 45 & 121 & 13 & 07 & 09 \\
\hline $69 \%$ & $31 \%$ & $80,6 \%$ & $8,7 \%$ & $4,7 \%$ & $6 \%$ \\
\hline
\end{tabular}

Fonte: Elaboração dos autores (2016)

Percebe-se que quase dois terços, 69\% dos participantes, representam ou estão vinculados a alguma instituição ou setor da administração pública. Isso significa que as demandas evidenciadas nas assembleias são em grande parte vinculadas a interesses de corporações organizadas previamente. Por exemplo, foi evidente em alguns lugares a participação em número expressivo de integrantes da polícia militar que traziam, entre suas demandas, recursos para aquisição desde coletes a viaturas.

A figura 2 mostra ainda a importância do convite para a participação em audiências e assembleias. Há necessidade de aprofundar a compreensão do sentido deste convite, mas pode-se operar com duas hipóteses não necessariamente excludentes. Por um lado, analisando conjuntamente os dados das figuras um e dois, poderia ser estimado que apenas um número reduzido de pessoas participou espontaneamente das assembleias e da consulta dado o caráter institucionalizado desta participação. Por outro lado, não se deve descartar o papel do convite como uma estratégia importante para a construção do poder local. Nas palavras de José Luis Rebelatto (s/d, p. 98), "a questão de como chegar ao vizinho 'não-organizado' adquire uma destacada relevância e, talvez, chave fundamental para o desenvolvimento de uma democracia radical" (tradução nossa) $^{7}$. A questão de fundo corresponde aos interesses que se consolidaram ao longo do orçamento participativo.

\section{PAULO FREIRE E A PARTICIPAC̣̃̃O}

Faz parte do senso comum pedagógico que a participação é fundamental para os professores e as professoras democráticos. Sabese também que a mesma está impregnada de muitos sentidos e é usada para finalidades muito diferentes. Por exemplo, a recente experiência de regimes totalitários indica a associação da participação com a 
simples adesão das massas a suas políticas; não menos manipulativas são as políticas populistas e assistencialistas. Por isso, na acepção freireana, a participação vem acompanhada do qualificativo popular. Cabe, uma breve incursão na história para contextualizar e melhor caracterizar essa perspectiva de participação.

Se tomarmos como ponto partida a civilização ocidental, com sua origem na Grécia Antiga, a ideia de participação é limitada aos homens livres, excluindo-se as mulheres e as crianças. Mesmo assim, a integração de cidadãos, camponeses, comerciantes e artesãos à comunidade política, uma novidade para o período, confere importância histórica para a democracia grega. Do ponto de vista dos contratualistas, em especial Jean-Jacques Rousseau, na condição de seres imperfeitos, os homens (sic) deveriam se contentar com democracias imperfeitas. Da mesma forma, portanto, mulheres não puderam garantir direitos como cidadãs e participar da coisa pública, assim como negros, embora se afirmasse a igualdade entre os homens (STRECK, 2005). Em relação aos indígenas, a condição de bárbaros, sem almas, não pode ser superada nem por uma bula papal. A mesma modernidade que hierarquizou homens e mulheres em relação à natureza estabeleceu o mito civilizatório como forma de justificativa para a violência do progresso e do desenvolvimento. A participação, portanto, "nasce" partida e se mantém na lógica do sistema-mundo (colonial-imperial-patriarcal-capitalista).

Por um lado, a participação está presente nos discursos dos organismos internacionais, como os do Banco Mundial, como sendo sinônimo de consulta cujo objetivo se vincula à ideia de "eficácia do desenvolvimento", "sustentabilidade", "pluralidade", "voluntariado", "responsabilidades social"; e, por outro lado, a participação se vincula aos projetos de sociedade dos movimentos sociais, o que implica em protagonismo dos sujeitos. Sendo assim, a compreensão de participação freireana não pode ser entendida sem os tensionamentos presentes na história na qual está inserida, o que se reflete na própria biografia de Paulo Freire.

Freire considera a democracia como algo muito maior do que apenas organização política, forma de gerir a coisa pública. Para ele, democracia é um modo de vida, uma prática constante que, sendo construída na relação dialógica, passa a ser interiorizada. É a efetivação da ideia que ele constantemente retoma, de que homens e mulheres devem envolver-se nos processos formadores de sua história, construindo-a com as próprias mãos enquanto se constroem 
a si mesmos. Outrossim, essa concepção tem a ver com a tolerância em relação às diferenças. O convívio com o diferente (seja de raça, ideologia política, religião), do mesmo modo que o repúdio a qualquer ato de discriminação são características de seu caráter democrático.

A partir de Freire, entendemos que a democracia, resultante da diversificação e da partilha das formas de poder político social, se insere, também, no conjunto de tensionamentos oriundos das relações entre a lógica sistêmica e a participação radical. Considerando que a lógica sistêmica corresponde ao que Habermas (2003) descreve como manifestação concreta do mundo sistêmico, composto pelos "subsistemas" econômico e administrativo, ao promover a reprodução material da sociedade, a participação acaba concebida de maneira estratégica. Enquanto a lógica sistêmica exige eficiência e objetividade em relação aos fins, a radicalidade democrática exige a participação ampla na tomada de decisões, fundamentada no diálogo. Ou seja, é sempre também um processo educativo.

As relações entre educação e participação se encontram no centro da teoria pedagógica de Paulo Freire (1976; 2008). Ainda que estivesse referindo-se a certo contexto social e histórico, as suas considerações sobre a vinculação entre a manutenção de privilégios sociais e o sistema educacional seguem sendo pertinentes ao tempo presente. Para ele, em uma sociedade alienada, inautêntica, onde imitar para resolver problemas significa desvalorizar o que é próprio (FREIRE, 1976), encontra-se também a descrença no poder fazer. Por outro lado, uma sociedade em movimento para a mudança favorece o surgimento de novas ideias e a autenticidade, como as de democracia radical por meio da participação popular. As massas, até então imersas em dada realidade, renunciariam à condição de expectadoras e exigiriam uma educação para a decisão, para a responsabilidade social e política (FREIRE, 2008). A democracia e a educação se fundam, precisamente, na crença na experiência do fazer do homem e da mulher. Numa sociedade fechada, a participação é anulada, enquanto que no processo de constituição de uma sociedade aberta, a participação vai se fazendo exigência. No trânsito entre uma sociedade e outra é que "as massas populares começam a se procurar e a procurar seu processo histórico" (FREIRE, 1976, p. 37) e, com isso, a participação vai se enraizando como aprendizado.

De acordo com Freire, as massas não apenas descobrem na participação um canal para a conquista da educação escolarizada, ou para outros direitos negados. Com a participação, também descobrem a perspectiva política que dela se pode derivar. A luta 
por elementos radicais de democracia, nesse sentido, é a tradução de sua exigência. Já na lógica do sistema, a que nos referíamos anteriormente, a participação se constitui em um impeditivo funcional. Democracia radical (participação radical) e administração se antagonizam nos processos políticos, fazendo com que a participação se restrinja a meros momentos estanques, como, por exemplo, as eleições. Racionalizada e condicionada, a participação é, concretamente, passiva e alienada, pois se acomoda ao modelo instituído. $\mathrm{Na}$ concepção democrática vigente, o poder político está assentado sobre bases hierárquicas, nas quais poucos decidem pela maioria. Logo, a essência democrática de participação popular jamais se efetiva. Pode-se identificar, aí, a violência do antidiálogo, a imposição do mutismo e da passividade que não oferecem condições para o desenvolvimento ou o trânsito das consciências em direção a uma maior criticidade. (FREIRE, 2008, p. 65).

Essa condição histórica, na compreensão freireana, é o ponto de partida a partir do qual se constroem novos horizontes. A experiência de alfabetização desenvolvida por Freire em Angicos, em 1963, se dá paradoxalmente no marco de projetos de governos, inclusive com o apoio financeiro advindo do controverso acordo entre o Ministério da Educação (MEC), do Brasil, e a United States Agency for International Development (USAID), agência de fomento norte-americana da Aliança para o Progresso ${ }^{8}$.Embora Paulo Freire ressaltasse que "a coordenação dos trabalhos deveria ser entre as lideranças universitárias" (apud FREIRE, 2006, p. 138), a alfabetização surge em meio a fortes conflitos políticos em nível nacional e internacional. Logo em seguida, ainda em 1963, a convite do então Ministro da Educação Paulo de Tarso, Paulo Freire assumiu a coordenação do Programa Nacional de Alfabetização (PNA) que viria a ser interrompido pelo golpe civil-militar em abril de 1964. Em retrospectiva, Paulo Freire comenta que naquele ano se vivia um momento de "profunda inquietação, de curiosidade, de presença popular nas ruas, nas praças" (FREIRE, 1991, p. 31) devido ao modelo populista que precisava do apoio das massas para se manter, equilibrando-se entre uma esquerda que buscava se viabilizar e uma direita que, como aconteceu, queria acabar com o movimento.

No período em que esteve no exílio (1964-1980), Paulo Freire experienciou a participação de diversas maneiras, constituindo novas tramas a partir de memórias que trazia do seu próprio corpo com a marca de novos fatos e novos saberes (FREIRE, 1992). No Chile, participou assessorando cursos de formação junto a camponeses 
nos assentamentos da reforma agrária. Também esteve engajado em campanhas de alfabetização em países do continente africano, como Angola, São Tomé e Príncipe, Cabo Verde e Guiné-Bissau. Entre abril de 1969 e fevereiro de 1970, Freire atuou como professor convidado na universidade de Harvard, vivenciando as contradições desde o âmago do poder econômico e intelectual.

A sua experiência frente à Secretaria Municipal da Educação em São Paulo revela os mesmos tensionamentos de quem, como diz, teve que "começar do começo mesmo." O gestor Paulo Freire não abdicou da participação, como explica: "Era impossível fazer uma administração democrática, em favor da autonomia da escola que, sendo pública fosse também popular, com estruturas administrativas que só viabilizavam o poder autoritário e hierarquizado.” (FREIRE, 1995, p.74). Para isso era preciso reconhecer o direito de voz aos alunos e às professoras, criar instâncias administrativas que facilitassem a ingerência dos pais e, por fim, o envolvimento da comunidade.

A participação para Freire é cultura. Quando homens e mulheres, em situações-limite compreendem a realidade, podem desafiá-la e procurar soluções. Na participação, os sujeitos enchem de cultura os espaços geográficos e históricos (FREIRE, 1976), pois a educação (libertadora) não é um processo de adaptação do indivíduo à sociedade. $\mathrm{Na}$ participação ativa, os homens e as mulheres se identificam com sua própria ação e, com isso, fazem-se história. A participação é um exercício de voz, de não-silenciamento, de decisão, de direito de cidadania que "se acha em relação direta, necessária, com a prática educativa-progressista" (FREIRE, 1995, p.73), com a democratização das estruturas sociais e da res-pública.

Como se pode observar, a compreensão de transitividade de uma sociedade a outra é tempo de possibilidades em Freire. Nesse processo, as massas passariam a exigir que sua voz fosse ouvida e perceberiam com mais facilidade as perspectivas que a educação pode abrir. Em se tratando do orçamento participativo, as pessoas se educam na medida em que, juntas, participam mais e melhor na vida em comunidade (FREIRE, 1989).

\section{CONTRADIC̣ÕES E TENSIONAMENTOS NA PRÁTICA DE PARTICIPAC̣ÃO}

Sendo sempre de natureza política, a educação na acepção freireana se situa dentro de relações de poder. Mais do que isso, tem como uma de suas principais funções explicitar e refletir essas relações desde uma perspectiva ética, fazendo perguntas sobre como 
este poder está sendo exercido, a serviço de quem ou de que setores ou classe está sendo posto, sobre a forma de tornar este poder partilhado de forma justa entre todos os cidadãos; enfim, trata-se de "democratizar o poder" (FREIRE, 1995, p.74).

A preocupação com a democratização do poder emerge de maneira muito forte a partir da década de 1980, com o fim da ditadura militar e com a possibilidade de viver sob uma constituição com princípios democráticos. Há, no entanto, o reconhecimento tácito ou explícito de que a superação da falta de experiência democrática denunciada por Paulo Freire já antes do golpe militar deveria ter como antídoto o desenvolvimento de práticas democráticas em organizações da sociedade civil e do estado. Ou seja, sabia-se que a democracia exigiria mais do que um formalismo legal para ter efetividade. Com isso, percebe-se que na inexperiência democrática que caracteriza a tradição política e social brasileira radicam, ao mesmo tempo, limites e possibilidades da democratização do poder.

Surgem nesse contexto experiências de exercício de democracia em escolas, em entidades sindicais e também em governos identificados como progressistas. Uma dessas experiências pioneiras no sul do Brasil se dá na cidade de Pelotas com o projeto "Todo poder emana do povo", liderado pelo prefeito Bernardo de Souza (1983-1987). Tratava-se de proporcionar espaços de discussão com a administração municipal e de criar mecanismos de participação direta do cidadão. Seria, como atestam depoimentos, uma forma de tornar a democracia indireta ou representativa mais eficiente (SOUZA, 2002).

Posteriormente, a participação é adotada em nível nacional como instrumento de controle fiscal, por meio da Lei Complementar $n^{\circ}$ 101/2000. Denominada Lei de Responsabilidade Fiscal, estabelece requisitos da participação popular na elaboração e transparência do orçamento público municipal, estabelecendo o seguinte no Art. 48:

São instrumentos de transparência da gestão fiscal, aos quais será dada ampla divulgação, inclusive em meios eletrônicos de acesso público: os planos, orçamentos e leis de diretrizes orçamentárias; as prestações de contas e o respectivo parecer prévio; o Relatório Resumido da Execução Orçamentária e o Relatório de Gestão Fiscal; e as versões simplificadas desses documentos. Parágrafo único. A transparência será assegurada também mediante: I - incentivo à participação popular e realização de audiências públicas, durante os processos de elaboração e discussão dos planos, lei de diretrizes orçamentárias e orçamentos; [...]

No entanto, foi na cidade de Porto Alegre, com o governo de Olívio Dutra (1989-1992) que se estruturou uma forma pioneira de participação no orçamento, considerado o núcleo duro da gestão 
pública. Essa experiência é depois levada para o governo do estado do Rio Grande do Sul na forma de Orçamento Participativo estadual, quando Olívio Dutra se torna governador (1999-2002), e reeditada no governo liderado pelo mesmo Partido dos Trabalhadores na administração Tarso Genro (2011-2014), porém com novos contornos. Assim, dentre os fatores das duas experiências de participação analisadas, os quais favorecem a democratização do poder, podem ser destacados os seguintes:

A estruturação de espaços de participação: Na perspectiva freireana o exercício do poder deveria evitar tanto o espontaneísmo quanto o dirigismo de uma vanguarda supostamente esclarecida. No orçamento participativo foi montada uma estrutura que, por um lado, identifica grandes áreas temáticas que são prioritárias para determinada região como saúde, educação e transporte, e, por outro lado, constrói propostas concretas desde a participação em assembleias municipais e regionais. O desafio, como se percebeu, é criar estratégias para a participação em escalas ampliadas, demográfica e geograficamente. É relativamente simples organizar a participação em grupos menores e em áreas geográficas restritas, mas os processos participativos adquirem níveis de alta complexidade na medida em que se amplia a população envolvida e a área de abrangência.

A possibilidade de "dizer a sua palavra" sobre a coisa pública em espaço público: O OP cria a possibilidade de cidadãos comuns, isto é, sem representação oficial, expressarem sua opinião sobre prioridades em termos de obras a serem executadas e da destinação de recursos públicos. Trata-se, em termos de Paulo Freire, do exercício da leitura de mundo, que para ele precede a leitura da palavra. Essa leitura de mundo se dá em diferentes níveis de complexidade, dependendo em grande parte do acesso a informações. As informações, como se observa no OP, são de naturezas distintas, ambas fundamentais: uma delas diz respeito ao funcionamento da máquina administrativa e do projeto do governo, sob responsabilidade dos gestores e coordenadores; a outra diz respeito aos dados sobre a realidade local e regional compartilhados pelos participantes do processo.

O estado como uma complexa correlação de forças e de projetos: A metáfora da trama que perpassa a Pedagogia da esperança (FREIRE, 1992) poderia servir para caracterizar o campo de disputas que compõem o estado. Aqui, gestores e cidadãos precisam portarse como educadores e educandos diante de uma realidade sempre em construção. Caberia, nas palavras de Nilton Bueno Fischer e Jaqueline Moll (2000, p.164), o desenvolvimento de "uma pedagogia, 
freireanamente elaborada na escuta densa!” Essa intencionalidade pedagógica estava muito clara desde a primeira experiência do OP no estado, quando se colocava explicitamente que não se trata de mero instrumento de reunir demandas.

No entanto, apesar dos avanços que o OP e o SISPARCI representam, não se pode idealizá-los como espaço de democratização do poder. Apontamos abaixo algumas das limitações percebidas a partir da análise de dados:

A redução da participação a uma estratégia administrativa: Se, por um lado, a participação necessita de estratégias que a viabilizem, ela não pode ser reduzida a mera estratégia de gestão. Paulo Freire reagia veementemente quando se tentava rotulá-lo como o criador de um "método" de alfabetização. Aliás, no próprio inquérito promovido pelos militares, eles procuraram "desmontar" a originalidade do "método", apontando semelhanças com outros métodos existentes. Eles estavam corretos ao minimizar a originalidade do "método" enquanto conjunto de técnicas, o que também não seria motivo para levá-lo à prisão. Eles também estavam certos - desde seu ponto de vista - que aqui estava em jogo algo muito mais fundamental e - isto sim - era motivo para silenciá-lo. Em outras palavras, a participação no sentido freireano está intimamente ligada com suas ideias de diálogo, de humanização e criação de autonomia como sujeito histórico, o que tem a ver com princípios de vida e organização social.

A distância entre dizer e ser ouvido: $\mathrm{O}$ fato de poder externar posições em lugares públicos, na presença de gestores que igualmente prestam contas de algumas ações do governo, é uma conquista importante. No entanto, há a necessidade de qualificar a escuta, dada a quantidade de filtros existentes entre a exposição de uma necessidade e a deliberação final sobre projetos. A possibilidade de manipulação é inerente a qualquer processo participativo e por isso cabe atentar para as mediações que se estabelecem. Um exemplo é a escolha do local da reunião ou assembleia: nota-se uma significativa diferença em termos de público se a mesma acontece num salão comunitário ou numa universidade. É de se supor que as pessoas se sintam mais à vontade para falar no local onde se encontram mais "em casa", no seu contexto cotidiano. Outra mediação importante diz respeito às autoridades instituídas que se fazem presentes nas reuniões para escutar, o que não necessariamente se traduzirá em aprovação do que estiver sendo proposto, mas no reconhecimento por parte de quem tem o poder de decidir.

O encontro, a conversa e o convite: $\mathrm{Na}$ perspectiva freireana, a participação requer diálogo, que por sua vez é o encontro respeitoso de 
reflexão mútua. Tanto o processo do Orçamento Participativo quanto o Sistema Estadual de Participação Popular e Cidadã, através dos dados de pesquisa, permitem identificar não só o valor deste diálogo, mas as expectativas a ele relacionadas. Primeiro, chama atenção que grande parte dos participantes registra que vieram às reuniões por convite (figura 2), ou seja, através de uma relação já existente com alguém (pessoas, corporações). Segundo, há uma avaliação de que a redução de espaços de discussão coletiva da primeira experiência (1999-2002) para a segunda (2011-2014)significou uma perda em termos de qualidade do processo. Ou seja, as pessoas gostariam de ter mais espaços onde discutir os seus projetos locais e regionais, bem como participar da discussão maior sobre as receitas e despesas do estado, não apenas de uma pequena parcela do orçamento já pré-estabelecida.

O descompasso entre as concep̧̧̃es administrativa e popular sobre as demandas emergentes, bem como sobre as condições para atendê-las: A população aponta suas necessidades concretas, elenca as mais importantes, alheia a princípios sistêmicos da administração pública, os quais condicionam ou mesmo impedem o atendimento do que é definido como prioridade. As atribuições das distintas esferas administrativas - municipal, estadual e federal, suas responsabilidades, por exemplo, não raro extremadas por questões político-partidárias, entram em rota de colisão. Ao mesmo tempo em que acabam secundarizando os interesses públicos em nome de interesses políticos, constata-se que o diálogo, alicerce da participação, não se consolida.

A concep̧̧ão econômica/mercadológica da democracia: A participação enfoca o aspecto orçamentário, contribuindo para consolidar uma concepção econômica e, ao mesmo tempo, sistêmica de cidadania e de democracia. Articulada, em grande medida, por iniciativas corporativas, a participação se processa de maneira condicionada, esvaziando e mesmo despolitizando o debate de seu teor coletivo. Os particularismos são majoritários, conduzindo o processo de acordo com a lógica sistêmica.

\section{CONSIDERACְÕES FINAIS}

Neste artigo partimos do pressuposto de que a participação popular nas decisões sobre o orçamento e nas políticas públicas, através de uma dinâmica que mescla espaços de democracia direta e representativa, não só busca inaugurar uma ferramenta de controle de execução de políticas, de obras e de serviços em nível estadual, como procura aperfeiçoar processos participativos. Observamos também 
que as ideias político-educativas de Paulo Freire tiveram um papel fundante na criação e implantação desta proposta no Rio Grande do Sul. Ou seja, o mérito da presença de Paulo Freire não está na oferta de um "menu" de técnicas ou instrumentos de participação, mas em evidenciar o caráter político-pedagógico de políticas sociais e de estratégias administrativas.

Em termos de democratização do poder, recorrendo a Paulo Freire como uma referência, analisamos o que de suas ideias é apropriado e como se dá essa apropriação através dos tensionamentos e contradições na prática da participação. Tanto nas possibilidades presentes na estruturação dos espaços de participação ativa da coisa pública, como no exercício de dizer a própria palavra, apropriandose de parte da "máquina" do Estado e das complexas correlações de forças atuantes, em cada um dos espaços. As etapas de realização do orçamento participativo e do SISPARCI tanto podem acionar forças mais localizadas quanto as gerais, como as demandas de uma escola ou de um movimento social ou administração municipal.

Ao lado desses aspectos que favorecem a democratização do poder, no entanto, há também outros que a limitam. Tais aspectos encontram-se na redução da participação no orçamento a uma estratégia administrativa ou eleitoral, ou ainda, na distância entre dizer e ser ouvido para que as necessidades e problemas locais e comunitários sejam, efetivamente, parte de uma proposta de inversão de prioridades. $\mathrm{Na}$ dinâmica do SISPARCI essas possibilidades foram ainda mais limitadas. Por exemplo, seria desejável do ponto de vista democrático que o orçamento público fosse debatido como um todo para que os cidadãos se apropriem dos dados e mecanismos do estado, superando o descompasso entre as concepções da administração e da população sobre as demandas emergentes face às condições para atendê-las.

Assim, na busca de respostas sobre o desenvolvimento (ou não) de processos formativos voltados para a democratização do poder em meio às experiências do orçamento participativo, nos deparamos com ambiguidades e contradições. A análise da participação concretizada nas experiências, a partir da concepção freireana, revelando-a mais estratégia do que princípio, é um indicativo dessa constatação. Portanto, ainda que não possamos ignorar o orçamento participativo ou o sistema de participação cidadã como experiências de democracia, nem mesmo considerar nulo o potencial de aprendizagem para a democratização do poder, entendemos que os distanciamentos são enormes em relação ao ideário de Paulo Freire.

A pergunta de fundo à qual remete a intersecção entre as pesquisas realizadas é a quem interessa de fato democratizar o poder 
na gestão pública. Vimos que em sua origem há um forte ímpeto de democratização que a institucionalidade tende a acomodar a interesses mais imediatos, seja de partidos ou de segmentos da população que se julgam no direito de dominar e controlar o que supostamente é público.

\section{REFERÊNCIAS}

BRANDÃO, C. R. Saber e ensinar: três estudos de educação popular. $2^{\mathrm{a}}$ ed. Campinas, SP: Papirus, 1986.

BOBBIO, N. O futuro da democracia: uma defesa das regras do jogo. Tradução de Marco Aurélio Nogueira. $4^{a}$ ed. Rio de Janeiro: Paz e Terra, 1986.

EAGLETON, T. Marx e a liberdade. São Paulo, SP: UNESP, 1999. (Coleção Grandes Filósofos). FEDOZZI, L. O poder da aldeia. Gênese e História do Orçamento Participativo de Porto Alegre. Porto Alegre: Tomo Editorial, 2000.

FISCHER, N. B., MOLL, J. (org.). Por uma nova esfera pública: a experiência do orçamento participativo. Petrópolis: Vozes, 2000.

FREIRE, A. M. A. Paulo Freire: Uma história de vida. São Paulo: Villa das Letras, 2006.

FREIRE, P. Política e educação. 2a ed. São Paulo: Cortez, 1995.

FREIRE, P. A educação na cidade. São Paulo: Cortez, 1991.

FREIRE, P. Pedagogia da esperança: Um reencontro com a pedagogia do oprimido. Rio de Janeiro: Paz e Terra, 1992.

FREIRE, P. Cartas a Cristina: reflexões sobre minha vida e minha práxis. $2^{a}$ ed. São Paulo: Editora UNESP, 2003.

FREIRE, P. Educação e Mudança.São, SP: Paz e Terra, 1976.

FREIRE, P. Educação como prática da liberdade. Rio de Janeiro, RJ: Paz e Terra, 2008.

FREIRE, P.; NOGUEIRA, A. Que faz̧er: teoria e prática em educação popular. $2^{\mathrm{a}}$ ed. Petrópolis, RJ: Vozes, 1989.

HABERMAS, J. Teoria de la acción comunicativa I. Madri: Taurus, 2003.

REBELATTO, J. L. Intelectual Radical. Compilado por Alicia Brenes, Maite Burgueño, Alejandro Casas y Edgardo Pérez. Montevideo: Extensón, Eppal y Nordan, s/d.

RIBEIRO, A. C. T.; GRAZIA, G. de. Experiências de Orçamento Participativo no Brasil. Período de 1997 a 2000. Petrópolis, RJ: Vozes, 2003.

RIO GRANDE DO SUL. Decreto n49.765 de 30 de outubro de 2012. Disponível em: http:/ /www. al.rs.gov.br/legis/M010/M0100018.asp?Hid_IdNorma=58558\&Texto=. Acesso em: 07 jul.2016.

SANTOS, B. de S. A crítica da razão indolente: contra o desperdício da experiência. Para um novo senso comum: A ciência, o direito e a política na transição paradigmática. $4^{a}$ ed., v. 1. São Paulo: Cortez, 2000.

SOUTO, V. Participação Popular e Cultura Política em Fortaleza (2004-2012). Fortaleza, CE: Expressão Gráfica e Editora, 2013.

SOUZA, B. Todo o poder emana do povo: Quando tudo começou. Pelotas: Educat, 2002.

STRECK, D. R. Por uma pedagogia da participação. In:STRECK, D. R. Dižer a suapalavra:educação cidadã, pesquisa participante, orçamento público. Pelotas, RS: Seiva, p. 85-114, 2005.

WEYH, C. B. Educar pela participação:uma leitura político-pedagógica do orçamento participativo estadual no município de Salvador das Missões/RS. Santo Ângelo: FURI, 2011. 


\section{NOTAS}

${ }^{1}$ De acordo com Santos (2000), a modernidade produziu dois tipos de conhecimentos: o conbecimento-regulação e o conbecimento-emancipação, o que implicou na tensão entre ambos, mas fundamentalmente a primazia do primeiro sobre o segundo. Tal relação fez da "ordem" a forma hegemônica do saber e do "caos" a forma hegemônica da ignorância.

${ }^{2}$ Esta atividade está vinculada ao projeto em nível nacional, coordenado por Ana Maria Saul (PUC-SP), que busca analisar o legado e a reinvenção de Paulo Freire em áreas como currículo, Educação de Jovens e Adultos, gestão e avaliação.

${ }^{3} \mathrm{O}$ SISPARCI integrava discussões e decisões sobre orçamento como uma das atividades do Sistema, um processo que era denominado por uns, como orçamento participativo ou consulta popular, por outros. No texto, a referência ao SISPARCI se refere especificamente às atividades pertinentes a questões orçamentárias.

${ }^{4}$ As primeiras experiências de descentralização de discussão e participação na decisão do orçamento público realizaram-se nos seguintes municípios brasileiros: Boa Esperança (Espírito Santo), em 1972; Lages (Santa Catarina), em 1976; Pelotas (Rio Grande do Sul), em 1983; Vila Velha e Vitória (Espírito Santo), São Paulo (São Paulo) e Porto Alegre, em 1989; Diadema (São Paulo), Recife (Pernambuco) e Belo Horizonte (Minas Gerais), em 1992. É importante ressaltar que nos três primeiros, não eram administrações petistas e, tampouco, assumiam as características e denominação de orçamento participativo. (WEYH, 2011).

${ }^{5}$ RIO GRANDE DO SUL. Decreto n ${ }^{\circ} 49.765$ de 30 de outubro de 2012. Disponível em: http://www.al.rs.gov.br/legis/M010/M0100018.asp?Hid_IdNorma=58558\&Texto=. Acesso em: 07 jul.2016.

${ }^{6}$ Estimativa da Fundação de Economia e Estatística do Estado do Rio Grande do Sul (FEERS) em 2015, disponível em: http://www.fee.rs.gov.br/indicadores/populacao/ estimativas-populacionais.

7 "el tema de como llegar al vecino no-organizado adquiere una relevancia destacada y quizás es uma clave fundamental para el desarrollo de uma democracia radical".

${ }^{8}$ Aliança para o Progresso foi um programa articulado pelo governo estadunidense de John F. Kennedy para integrar os países latino-americanos. Destaca-se o seu movimento estratégico para o desenvolvimento dependente desses países no contexto de Guerra Fria.

Submetido: $14 / 08 / 2016$

Aprovado: 31/01/2017

Contato:

Danilo R. Streck

Rua Pastor Rodolfo Saenger, 144

Bairro Jardim América

São Leopoldo |RS|Brasil

CEP 93.035-110 